\title{
Influencia de la fotografía digital en los departamentos de documentación de prensa
}

\author{
Por Juan-Miguel Sánchez-Vigil, Juan-Carlos Marcos-Recio y María Olivera-Zaldua
}

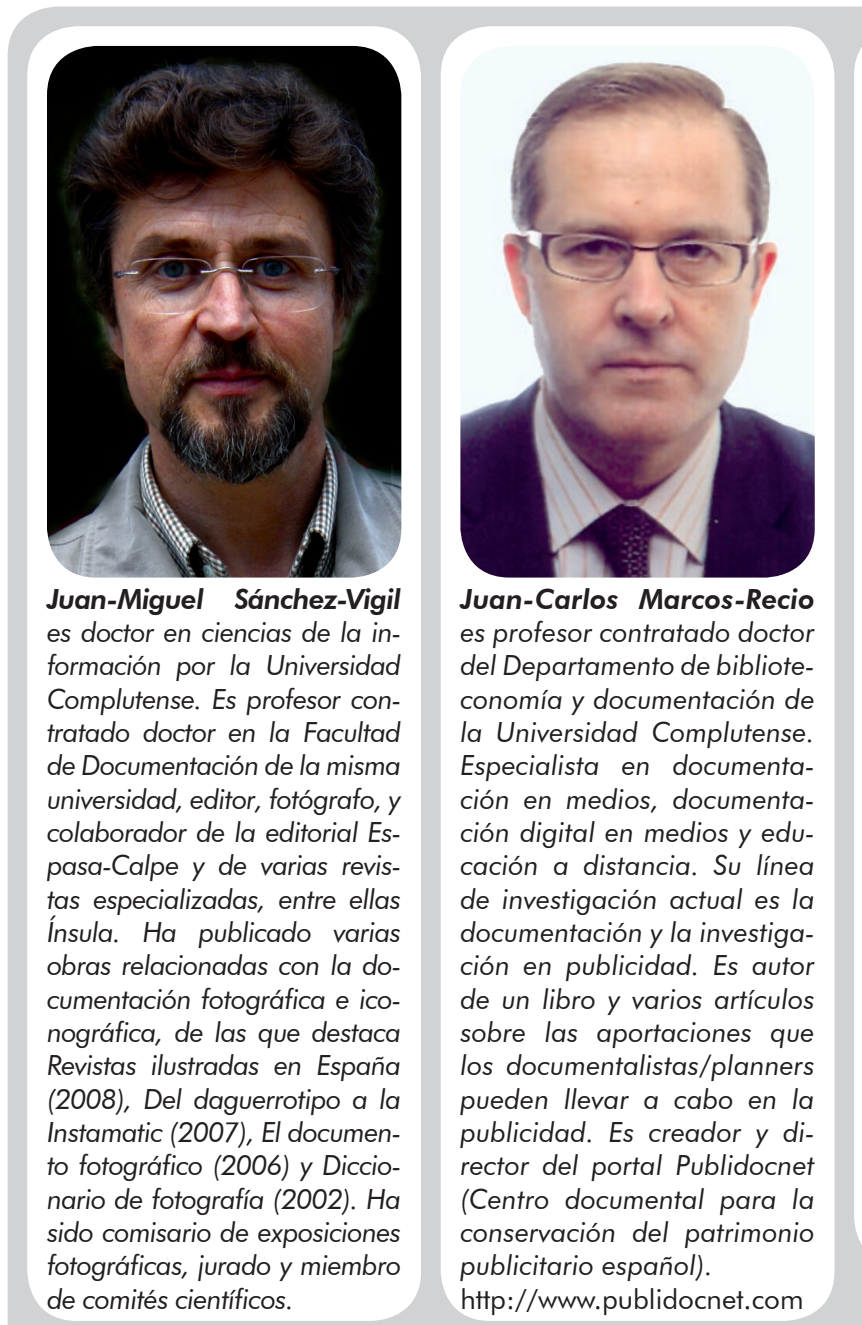

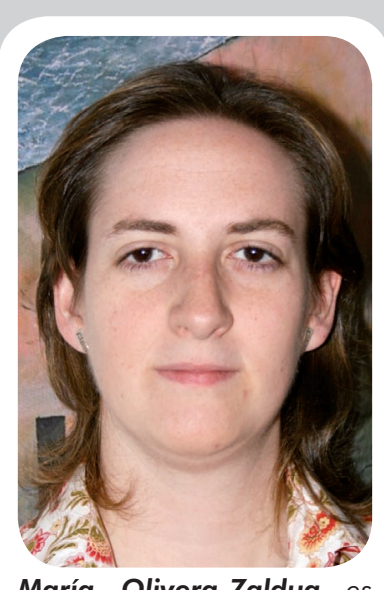

María Olivera-Zaldua es licenciada en documentación por la Universidad Complutense. Estudiante de doctorado en la Facultad de ciencias de la información, con DEA sobre el Archivo iconográfico de Joaquín Turina. Es documentalista de la editorial Espasa-Calpe en varias obras y forma parte del equipo de investigadores del Archivo del Ateneo de Madrid. Ha colaborado en los libros Revistas ilustradas en España y Del daguerrotipo a la Instamatic y es autora de varios artículos y comunicaciones. Colabora en el blog "Documentación" en Weblogs mitd.
Resumen: Estudio del impacto y la influencia de la fotografía digital en los departamentos de documentación de prensa. Se toman como referentes los fondos fotográficos de los departamentos de documentación de los diarios $A B C$, El mundo, El país, La razón, La vanguardia, y la agencia de noticias EFE. Se analizan los siguientes aspectos: aumento del número de imágenes, cambios en tratamiento y catalogación, ofertas y demandas, rentabilidad y problemática. Los datos han sido obtenidos de los responsables de los centros mediante un cuestionario elaborado con este propósito.

Palabras Clave: Fotografía, Fotografía digital, Documentación fotográfica, Archivos fotográficos de prensa, $A B C, E F E$, El mundo, El país, La razón, La vanguardia.

Title: The influence of digital photography on the Documentation departments of the Press

Abstract: A study of the impact and influence of Digital Photography on the Press Documentation Departments. The photographic archives of the Documentation Departments of the Spanish daily newspapers ABC, El mundo, El país, La razón, $L a$ vanguardia and of the EFE news agency are used as reference. The following aspects are analysed: the increase in the number of images, changes in their handling and cataloging, the supply and the demand, profitability and problems. The information has been obtained from the heads of the respective departments based on a questionnaire especially drawn up for this purpose.

Keywords: Photography, Digital photography, Photo documentation, Photo files from the press, ABC, EFE, El mundo, El país, La razón, La vanguardia.

Sánchez-Vigil, Juan-Miguel; Marcos-Recio, Juan-Carlos; Olivera-Zaldua, María. "Influencia de la fotografía digital en los departamentos de documentación de prensa". El profesional de la información, 2009, mayo-junio, v. 18, n. 3, pp. 278-283.

DOI: 10.3145/epi.2009.may.04

\section{Introducción}

Las versiones impresas y digitales de los periódicos, y por extensión otros productos del sector editorial, han sufrido una transformación radical en lo que respecta al uso y aplicación de la fotografía (SánchezVigil, 2002). Esta transformación ha provocado en los departamentos de documentación de los diarios la modificación de los métodos tradicionales de trabajo. 
La presión para realizar cambios llegó primero a los departamentos de fotografía y en seguida a los de documentación, encargados del tratamiento, conservación y difusión de las imágenes para su posible reutilización (Tejedor, 2008; Periago, 2000; Robledano, 2000).

La valoración global de tales cambios es el objeto de estudio de este trabajo mediante un cuestionario dirigido a los responsables de documentación, objeto que sin duda posibilita aproximaciones desde otros puntos de vista, como los aspectos éticos, los derechos de autor, la responsabilidad de los documentalistas en la selección de imágenes que conforman el fondo, etc.

Los aspectos estudiados se han estructurado en cuatro grupos: cuestiones generales, funcionamiento y usuarios, contenidos y digitalización, y rentabilidad.

De manera concreta, la pretensión es conocer en cuánto tiempo se llevaron a cabo los cambios, su influencia en el tratamiento de los contenidos, la evolución de los recursos humanos, la aplicación de la tecnología, la rentabilidad derivada de los nuevos métodos de trabajo y la respuesta de las empresas a todas estas cuestiones.

En el análisis tomamos como referentes los archivos fotográficos de los departamentos de Documentación de algunos de los principales diarios de cobertura nacional y mayor tirada, a los que se añade la agencia EFE por su actividad y servicio. Se trata por tanto de paradigmas en la comunicación en España por sus colecciones fotográficas en calidad y en cantidad.

Este trabajo ha sido posible gracias a la colaboración de los directivos de estos departamentos: Federico Ayala $(A B C)$, Concha Tejedor $(E F E)$, Juan-Antonio Jiménez, Ana García-de-Viedma y Alicia GarcíaAmilburu (El mundo), Juan-Carlos Blanco (El país), Alejandra Tahoces (La razón) y Carles Salmurri ( $L a$ vanguardia).

\section{Digital versus formato tradicional: el proceso de cambio}

La entrada de la fotografía digital en los archivos de la prensa fue progresiva, siguiendo la estela del cambio de cámaras en las secciones de Fotografía. Se llevó a cabo durante los cinco últimos años del siglo XX (gráfico 1), con El país como pionero al iniciar el tratamiento en febrero de 1994, seguido de $A B C$ en mayo de 1995 , El mundo en junio de 1995, La razón desde 1998 y La vanguardia desde los primeros meses de 1999. Carles Salmurri, responsable de documentación de este diario, presentaría tres años después la base de datos del Grupo Godó (empresa editora) en El profesional de la información (Salmurri et al, 2002). La agencia EFE, por su parte, realizó las primeras adaptaciones a partir de octubre de 1998, poco después de La razón.

Los departamentos de Fotografía comenzaron a cambiar las cámaras a mediados de los noventa y ese fue el punto de partida para las secciones de Documentación, que tuvieron que reaccionar con inmediatez para evitar la acumulación de documentos en los servidores (Chacón, 1994). Sin embargo, la respuesta de las empresas fue lenta, aun sabiendo que la digitalización del fondo en formato tradicional permitiría una explotación continua sin necesidad de volver a emplear los negativos o positivos, con el consiguiente ahorro de tiempo y material.

"Los departamentos de Fotografía cambiaron las cámaras a mediados de los noventa y ese fue el punto de partida para las secciones de Documentación"

En el período de adaptación o transición se emplearon tiempos prolongados en casi todos los casos. $A B C$ realizó un primer plan de choque entre mayo y noviembre de 1995, para continuar la labor hasta mediados de 1999, coincidiendo con el cambio de diseño del diario. El país invirtió cuatro años entre 1994 y 1998, en El mundo se empezaron a tirar fotografías digitales en el segundo semestre de 1995 y el cambio definitivo se realizó en el verano del 2000; La vanguardia empleó cuatro años entre 1999 y 2002, en EFE la adaptación

\begin{tabular}{|c|c|c|c|c|c|c|c|c|c|}
\hline & 1994 & 1995 & 1996 & 1997 & 1998 & 1999 & 2000 & 2001 & 2002 \\
\hline$A B C$ & & & & & & & & & \\
\hline$E F E$ & & & & & & & & & \\
\hline El mundo & & & & & & & & & \\
\hline El país & & & & & & & & & \\
\hline La razón & & & & & & & & & \\
\hline La vanguardia & & & & & & & & & \\
\hline
\end{tabular}

Gráfico 1. Período de incorporación de la fotografía digital a los departamentos de Documentación 
fue más rápida y culminó en diciembre de 2000 y $L a$ razón fue el último en cerrar los procesos en 2002. Por entonces las imágenes reproducidas en los diarios impresos eran las mismas que en las ediciones digitales (Caminos-Marcet, 2006).

Los profesionales coinciden en señalar varios aspectos, si bien con matices: la digitalización permite sobre todo salvar de una destrucción segura, por el paso del tiempo, las imágenes; por otra parte, consideran que los originales sufren menos, ya que una vez digitalizados no es necesario manipularlos para obtener copias. Otra de las observaciones positivas es la recuperación gracias a los buscadores y a la facilidad de archivo, lo que mejora el rendimiento de los documentalistas. En cuanto a la difusión, concluyen que internet hace posible el acceso universal para investigación o publicación.

Carles Salmurri, responsable de la documentación en La vanguardia indica que el verdadero cambio se produjo en el momento en que las fotografías pudieron ser almacenadas en alta resolución y en bases de datos estructuradas por campos. En ese momento "invertimos la pirámide del tiempo", porque el documentalista dedicaba gran parte del tiempo al trabajo manual (distribución y archivo de copias), y lo ganó en favor de las tareas propias de la documentación (indexación temática, descripción de la imagen y redacción de pies de foto).

\section{Tratamiento documental}

La fotografía digital ha supuesto un nuevo tratamiento documental y en consecuencia una inversión en equipos y software para la recuperación de las imágenes, cuestión ya planteada a finales del siglo XX (Valle-Gastaminza, 1999; Robledano-Arillo, 2000). No tratamos aquí aspectos cualitativos de la imagen (Abreu, 2004) sino su análisis global. Los proyectos se llevaron a cabo por dos vías: mediante encargo a empresas externas de acuerdo con las necesidades específicas, y siguiendo diseños propios adaptados al uso interno. En todos los casos, con excepción de El país y La razón, se han modificado los sistemas de catalogación, e igualmente ha sido necesaria la inversión en equipos informáticos (hardware y software).

A modo de referencia indicamos que, en todos los centros, el proceso de entrada y tratamiento es similar: el departamento de fotografía recibe las imágenes de los profesionales, selecciona las que considera adecuadas para sus intereses (valor informativo) y permanecen en su poder un tiempo concreto -relativamente corto- hasta que pasan al sistema de gestión documental. Comienza entonces el proceso de catalogación y análisis. El número de fotografías que se examinan a diario

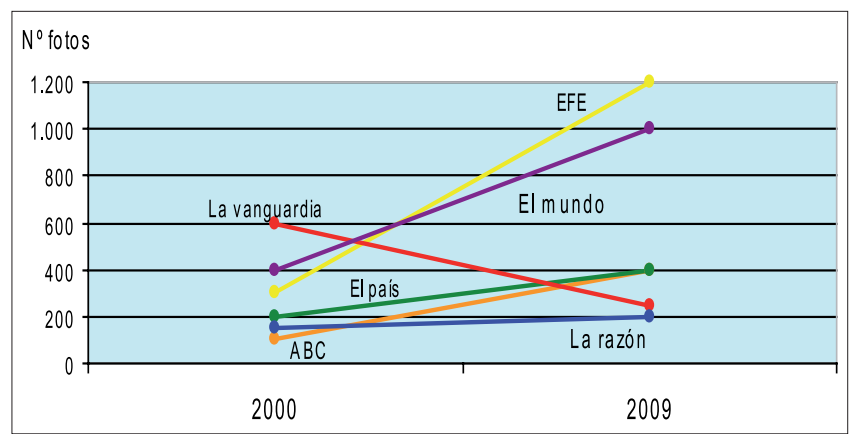

Gráfico 2. Fotos analizadas por día. Comparativa: 2000-2009

ha aumentado considerablemente en todos los medios (gráfico 2), excepto en el caso de La vanguardia, donde se ha reducido en un $140 \%$. En este diario se llevó a cabo un proceso de digitalización masiva que alcanzó en 2004 las 400.000 imágenes, realizado por una empresa externa con recursos internos; la digitalización actual no la realiza el departamento de Documentación sino el de Fotografía. En la agencia EFE se trataban en el año 2000 una media diaria de 300 imágenes, mientras que en 2009 se han superado las 1.200; es decir, que el número de imágenes preparadas por jornada se ha multiplicado por cuatro, con un $20 \%$ más de personal. En $A B C$ y El país las cifras del año 2000 son estimativas y actualmente se analiza una media de 400 fotografías; en La razón las unidades por día superan las 200 frente a las 150 del año 2000.

\section{"El número de fotografías que se analiza diariamente ha aumentado considerablemente en todos los medios"}

Otro aspecto de interés es la digitalización de los fondos en formato tradicional, una tarea rentable que no se realiza con fluidez, sino que depende de las demandas, debido a la falta de recursos humanos. En todos los casos, excepto en el diario La razón donde la falta de personal no lo ha permitido, la digitalización la han efectuado profesionales de los departamentos de Documentación siguiendo los programas de trabajo de la propia empresa. La digitalización de los fondos históricos o de mayor interés ha permitido recuperar materiales olvidados, susceptibles de ser rentabilizados mediante proyectos específicos; en esta tarea ha marcado la pauta $E F E$, como veremos más adelante, con la publicación de varios libros ilustrados. La escasa recuperación de fondos se debe, según Alejandra Tahoces de La razón, a que "la actualidad manda y pocas veces se necesita recurrir a negativos del año $2001 \mathrm{o}$ anteriores". 


\section{Sobre los contenidos y la rentabilidad de tiempos y espacios}

El número de imágenes que ingresa en los departamentos de Documentación se ha duplicado en casi todos los casos (gráfico 3). En EFE o El país supera el $100 \%$, en La vanguardia y El mundo se sitúa entre el 40 y el $60 \%$, en $A B C$ entre el 80 y el $100 \%$, y en $L a$ razón entre el 20 y el $40 \%$, teniendo en cuenta que este diario salió en 1998. En La vanguardia, el fondo antes del proyecto de digitalización constaba de 1.200.000 imágenes en soporte papel, 30.000 diapositivas, 5.000 unidades en otros formatos y 3.500 .000 negativos. Las cifras se mantienen en el 2008, excepto en el soporte papel, reducido a 900.000 positivos. Todos los negativos han sido digitalizados, con el $1 \%$ disponible online y el resto offline.

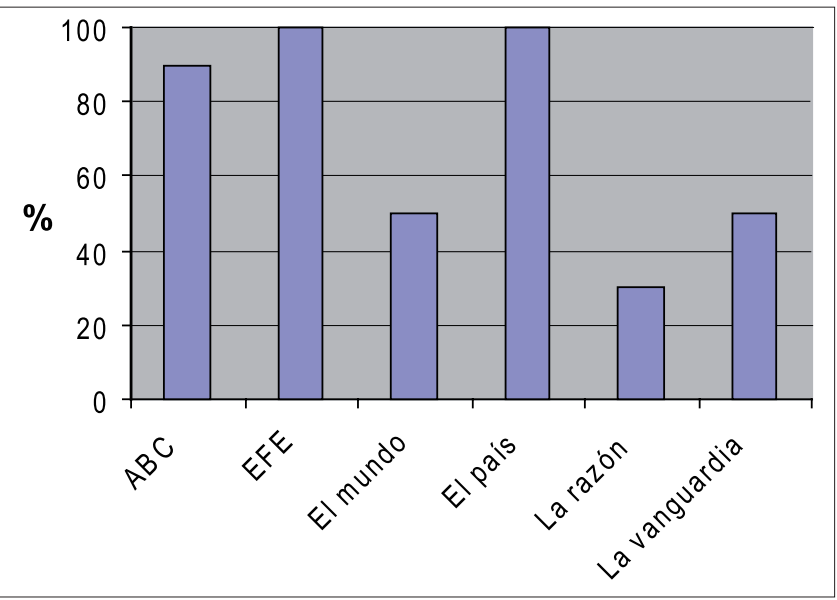

Gráfico 3. Porcentaje del aumento de fotografías en los archivos entre 1995 y 2009

La mayor entrada de documentos no conlleva sólo lecturas positivas, ya que el número de imágenes que ingresa no significa que aumente la diversidad temática sino las fotografías en relación con cada tema, lo que obliga a dedicar más tiempo a la selección o bien a la catalogación. Como indica Alejandra Tahoces ( $\mathrm{La} \mathrm{ra}$ zón): "En este sentido prima el volumen, no la calidad. Hay una menor selección de lo que se cataloga; digamos que en la práctica se cataloga casi todo por falta de tiempo para hacer una selección en condiciones".

El conjunto de documentos de los seis medios estudiados suma cerca de setenta millones, con un $20 \%$ digitalizado y el resto en los formatos tradicionales (gráfico 4). Sólo El mundo y La razón disponen de un fondo digitalizado mayor que el tradicional. La agencia EFE, con 15.000.000 de fotos en sus fondos y en una política acertada de recuperación de contenidos, apostó por la digitalización de los documentos históricos (Tejedor, 2009), al tiempo que inició la publicación de obras ilustradas de calidad que no sólo aportan documentos para el estudio de la historia sino que proyectan la imagen de la empresa. Son ejemplos los libros: 1900-2000 un siglo de España (2001), Imágenes inéditas de la Guerra Civil, 1936-1939 (2002), e Imágenes insólitas de una dictadura, 1939-1975 (2002). También ABC, con 25.000.000 de fotografías en su archivo, ha sacado a la luz sus fondos mediante publicaciones específicas, con el fin de difundirlos y rentabilizarlos. Estas actitudes han tenido una respuesta interna con el uso de las fotografías en algunas de las publicaciones especializadas como $A B C D$ cultura y arte, ilustrada con los fondos históricos, y también externa al provocar mayor demanda de dichos fondos. En el caso de El país, con 12.000.000 de fotografías, también sus imágenes históricas han sido utilizadas en "productos" para el gran público, como los coleccionables sobre la transición española.

\section{"Todos los medios tienen el fondo a disposición de los profesionales mediante intranet, con tiempos de respuesta mínimos"}

Por lo que respecta al acceso a los contenidos, todos los medios tienen el fondo a disposición de los profesionales mediante intranet, con tiempos de respuesta mínimos. La agencia $E F E$ tiene su fondo a disposición de sus abonados y concede licencias temporales para proyectos concretos mediante acuerdos. La reducción en los tiempos de respuesta ha cambiado los ritmos variables y lentos por constantes y rápidos: en $E F E$ el servicio es inmediato, $A B C$ ha reducido las entregas por unidad de 30 minutos a 15 , y en los demás diarios la recuperación es casi inmediata.

La imagen digital ha repercutido en una mayor rentabilidad de los departamentos por la rapidez de respuesta, la cantidad de fotos documentadas, la calidad del análisis y el ahorro de espacio (Sánchez-Vigil; Marcos-Recio; Villegas-Tovar, 2007), que en el caso de El país ha supuesto un $100 \%$ recuperado para otros usos. Sin embargo, el espacio ha sido y continúa siendo, por la cantidad de fondos tradicionales conservados (papel, negativos y otros soportes), uno de los caballos de batalla y así lo señala especialmente El mundo, ya que se trata de una de las cargas de las empresas por el precio de alquiler o compra del suelo. $A B C$ ha recuperado una línea de investigación para valorar los paradigmas desde los que se obtiene la rentabilidad, sintetizados en mayor capacidad de almacenamiento, mejor gestión, versatilidad en la producción de recursos y seguridad de los originales. La excepción es el diario La razón, cuyo problema no es el espacio físico sino el almacenamiento en discos. 


\begin{tabular}{|l|c|c|c|c|c|c|}
\hline & El país & EI mundo & La vanguardia & ABC & EFE & La razón \\
\hline $\begin{array}{l}\text { Fondo en formato } \\
\text { tradicional }\end{array}$ & 11.000 .000 & 2.200 .000 & 4.735 .000 & 24.000 .000 & 12.000 .000 & 40.000 \\
\hline Fondo digital & 1.000 .000 & 3.800 .000 & 4.340 .056 & 1.000 .000 & 3.000 .000 & 2.000 .000 \\
\hline Total & 12.000 .000 & 6.000 .000 & 9.075 .056 & 25.000 .000 & 15.000 .000 & 2.040 .000 \\
\hline $\begin{array}{l}\text { Digitalizadas de } \\
\text { archivo }\end{array}$ & Sin valorar & 250.000 & $\begin{array}{c}\text { Negativos: } \\
\text { Positivos: } \\
240.000\end{array}$ & 400.000 & 300.000 & $\begin{array}{c}\text { No se han } \\
\text { digitalizado }\end{array}$ \\
\hline
\end{tabular}

Gráfico 4. Fondos fotográficos en 2009

\section{Recursos humanos}

En el período comprendido entre los años 2000 y 2009, los departamentos de Documentación de prensa han sufrido cambios estructurales con excepción de EFE y El país. En este aspecto, el impacto ha sido negativo en todos los casos, excepto en el de la agencia EFE (tabla 1).

La respuesta de las empresas ante las nuevas necesidades fue el reciclaje y formación de los profesionales, con excepción de La vanguardia y La razón. En el primero la plantilla se ha reducido en un $50 \%$ (de seis a tres profesionales) y en el segundo en un 33\% (de seis a cuatro). En $A B C$ el total de documentalistas en el año 2000 era de diecinueve, la mitad dedicados a la fotografía, y en el 2009 los profesionales son diez, de los que siete trabajan con las fotografías. El país es el único que ha mantenido la plantilla con el mismo número de documentalistas a lo largo de la década: seis profesionales, tres de ellos a tiempo completo y otros tres a tiempo parcial, compartido con otras tareas.

La fotografía digital, la aplicación de las bases de datos y, sobre todo, la posibilidad de recuperación inmediata que sustituyó al proceso tradicional de los archivos, confirman que los tiempos empleados en la búsqueda, localización y preparación del material para su entrega se redujeron considerablemente. Por otro lado, es importante señalar que no han sido sólo éstos los motivos de la reducción, sino que han influido otros aspectos relacionados con las políticas de empresa. Carles Salmurri advierte que en La vanguardia la reducción no ha sido sólo causa directa del cambio del formato tradicional al digital. En el diario El mundo parte del trabajo de documentación lo realizan los propios autores de las fotografías cumplimentando la información solicitada en los campos IPTC (incluyen los metadatos que definen las características de la imagen), tarea que completan los fotógrafos del mismo departamento, quienes insertan los datos.

Por último, un dato importante relacionado con la salida de profesionales desde la Universidad: todos los medios de Madrid han recurrido a profesionales y a becarios formados en las facultades de documentación de las universidades públicas de la Comunidad de Madrid.

\begin{tabular}{|l|c|c|}
\hline & Año 2000 & Año 2009 \\
\hline Abc & 10 & 7 \\
\hline EFE & 18 & 22 \\
\hline El mundo & $7-10$ & 4 \\
\hline El país & $6(3 \mathrm{TC}+3 \mathrm{TP})$ & $6(3 \mathrm{TC}+3 \mathrm{TP})$ \\
\hline La razón & 6 & 4 \\
\hline La vanguardia & 6 & $2-3$ \\
\hline
\end{tabular}

Tabla 1. Número de documentalistas gráficos TC: tiempo Completo; TP: tiempo parcial

\section{Problemáticas y conclusiones}

La mayor preocupación de todos los centros es la falta de personal y de presupuesto para acometer los proyectos y atender las necesidades de los departamentos de Documentación. En ninguno de los casos existen problemas en relación con los recursos técnicos. Los dos aspectos indicados son vitales para acometer la digitalización y el análisis de los documentos, actividades que abren nuevas vías de rentabilidad. Se trata de un bucle que sólo puede romperse con políticas adecuadas de inversión a corto y medio plazo (gráfico 5).

Del análisis de la influencia de la fotografía digital en los departamentos de Documentación de los principales diarios, así como de la agencia EFE se concluye:

- El cambio en los departamentos de Documentación se produce gracias a la posibilidad de almacenar millones de originales en alta resolución, a su mejor tratamiento con las bases de datos y a su recuperación inmediata.

- La fotografía digital ha permitido analizar mayor número de imágenes y profundizar en el estudio de sus contenidos, de lo que se deriva mayor posibilidad de reutilización y rentabilización del fondo (interna y externa).

- Los modelos de trabajo y las prioridades en los 


\begin{tabular}{|l|l|l|l|l|l|l|}
\hline & ABC & EFE & El mundo & El país & La razón & La vanguardia \\
\hline Personal & & & & & & \\
\hline Tecnología & & & & & & \\
\hline Tiempo & & & & & & \\
\hline Presupuesto & & & & & & \\
\hline
\end{tabular}

Gráfico 5. Problemática de los departamentos de Documentación

\section{"De manera directa o indirecta, la fotografía digital es causa de la reducción de plantillas en los departamentos de Documentación"}

departamentos, aun siendo comunes los objetivos generales, varían según las necesidades internas.

- En general, el problema es la falta de presupuesto y de personal para acometer tareas con las que rentabilizar los fondos.

- De manera directa o indirecta, la fotografía digital es causa de la reducción de plantillas en los departamentos de Documentación.

\section{Referencias bibliográficas}

Abreu, Carlos. "El análisis cualitativo de la foto de prensa". Revista latina de comunicación social, n. 57, julio 2004

Aguado-Gonzalez, Francisco-Javier. "Organización del sistema de archivo y documentación de prensa española ( $A B C$ y Blanco y Negro)". Revista general de información y documentación, 1995, n. 5, pp. 203-208.

Aguilera, Begoña; Lehner, Richard. "La documentación de prensa bajo la luz de la tecnología: el futuro de hoy". Anuari de Biblioteconomia, Documentació i Informació Bibliodoc 2000, 2000, pp. 21-32.

Caminos-Marcet, José-María; Murillo, Flora-María; Armentia-Vizuete, José-Ignacio. "El uso de la fotografía en los diarios digitales españoles", Comunicación y sociedad, 2006, v. XIX, n. 2, pp. 9-38.

Chacón-Gutiérrez, Inmaculada. "Efectos sociales del proceso documental de la fotografía en prensa". Cuadernos de documentación multimedia, 1994, n. 3, pp. 17-23.

Fernández-Álvarez, Eloína et al. "Los servicios de documentación en prensa”. Cuadernos de documentación multimedia, n. 6-7, 1997-1998.

Fernández-Bajón, María Teresa. "Centros de documentación en prensa: una aplicación a los semanarios de información general". Revista general de información y documentación, 1994, v. 4, n. 2, pp. 97-106.

Periago-García, Lucía. "Evolución de los sistemas de almacenamiento y distribución de la fotografía en el diario regional La verdad". El profesional de la información, 2001, v. 10, n. 10, pp. 12-21.

http://www.elprofesionaldelainformacion.com/contenidos/2001/octubre/2.pdf

Periago-García, Lucía; Pagán-Valera, Francisco. "Seguimiento informatizado de un sistema digital de archivo y documentación de fotografías en un periódico regional". En: Jornadas españolas de documentación automatizada, 1996, pp. 761-768

Periago-García, Lucía; García, Juan-Carlos; González-Olivares, JoséLuis. "Posibilidades de la gestión de información de prensa en entornos digitales para bibliotecas". En: XI Jornadas bibliotecarias de Andalucía, Sevilla, 2000, pp. 651-664.

Robledano-Arillo, Jesús. El tratamiento documental de la fotografía de prensa. Madrid: Archiviana, 2002.

Robledano-Arillo, Jesús. El análisis documental de la fotografía de prensa en entornos automatizados. Tesis Doctoral. Madrid: Universidad Carlos III, 2000 .

Salmurri, Carles; Abadal, Ernest; Sancho, Mónica; Llevat, Miquel; Sulé-Duesa, Andreu; Corbera, Maita. "Diseño y creación de la base de datos documental del Grupo Godó". El profesional de la información, 2002, v. 11, n. 3, pp. 195-204.

http://www.elprofesionaldelainformacion.com/contenidos/2002/mayo/7.pdf

Sánchez-Hernández, María-F. “Automatización de un archivo fotográfico en un medio de comunicación”. En: IX Jornada Bibliotecaria de Andalucía, Granada, 1996, pp. 271-276.

Sánchez-Vigil, Juan-Miguel. "Archivos fotográficos en prensa”. -Cuadernos de documentación multimedia, 2002, n. 12, pp. 1-52.

Sánchez-Vigil, Juan-Miguel; Marcos-Recio, Juan-Carlos; Villegas-Tovar, Ricardo. "Los recursos fotográficos en los periódicos digitales: valores de la fotografía digital". Ibersic: revista de sistemas de información y documentación, 2007, n. 1, pp. 211-218.

Tejedor-F.-Escribano, Concha. "Digitalización de un archivo fotográfico de prensa y su difusión en internet”. En: ¿Qué hacemos con la fotografía en los archivos? Córdoba: Ayuntamiento, 2008.

http://archivo.ayuncordoba.es/Agenda.htm

Valle-Gastaminza, Félix del. "El análisis documental en la fotografía". En: Manual de Documentación Fotográfica. Madrid: Síntesis, 1999, pp. $113-$ 131.

\section{Juan-Miguel Sánchez-Vigil, María Olivera-Zaldua}

Universidad Complutense de Madrid. Facultad de Ciencias de la Documentación. Santísima Trinidad, 37, 28010, Madrid.

jmsvigil@telefonica.net

molizal@hotmail.com

\section{Juan-Carlos Marcos-Recio}

Universidad Complutense de Madrid. Facultad de Biblioteconomía y Documentación. Edificio Nuevo. Avda Ciudad Universitaria, s/n, 28040, Madrid.

jmarcos@ccinf.ucm.es 